\title{
Stock Price and Trading Volume during Market Crashes
}

\author{
Rodion Remorov ${ }^{1}$ \\ ${ }^{1}$ Independent Consultant, Canada \\ Correspondence: Dr. R. Remorov, 54 Southvale Dr., Vaughan, Ontario, Canada, L6A0Y6. E-mail: \\ rodionremorov@gmail.com
}

Received: October 2, 2013

Accepted: November 6, 2013 Online Published: January 22, 2014

doi:10.5539/ijms.v6n1p21

URL: http://dx.doi.org/10.5539/ijms.v6n1p21

\begin{abstract}
We present a model for stock price and volume behaviour during market crashes. The model incorporates a market mechanism for the share exchange between buyers and sellers while taking into account their cash balances. Using an analytical approach and the Monte-Carlo technique for the simulation of the trading volume, we analyzed the dynamics of the stock price and trading volume during market crashes. The trading volume was simulated through the trading exchange process using Monte-Carlo technique. We found that trading volume is inversely proportional to the square of the stock price in the case of the sharp price declines. This result is empirically supported in price and volume data for major recent US stock bankruptcies and market crashes, including Lehman Brothers Inc, Enron, Wachovia, Washington Mutual, Citigroup, Merrill Lynch, and MF Global. The results of the analytical approach may be used for marketing analysis of the sales in the case of the shocking market conditions.
\end{abstract}

Keywords: stock price, trading volume, market crash, panic, behaviour, Monte-Carlo simulation

\section{Introduction}

Stock price modeling has an extensive empirical and theoretical research history. Existing mathematical models have mainly focused on the empirical investigation of the time-series of price returns and volatility. Two main fundamental assumptions of stock price dynamics are important. The assumption of the random walk of the return movement was suggested by Bachelier in 1900. Stock returns were considered as a series of independent "shocks", which, by the Central Limit theorem, leads to the Gaussian distribution of returns. The Efficient Markets Hypothesis (EMH) plays a key role in the assumption of the random walk, which allows to widely use the Black-Scholes paradigm for the valuation of the derivative instruments (Black \& Scholes, 1973). The EMH assumes that market participants possess homogeneous information, and therefore the hypothesis can be applied in limited real-life settings. Numerous empirical studies have shown that the stock market does not follow a random walk. Lo and MacKinlay (1988) used the Dickey-Fuller test to demonstrate that the Random Walk Hypothesis is violated over short horizons. Mandelbrot (1963) demonstrated that price crashes occur much more frequently than what would be predicted by a log-Normal distribution. Mandelbrot suggested that the exchange of money as an economic interaction can be considered by analogy as the exchange of energy between gas-phase molecules. Chatterjee and Chakrabarti (2007) empirically showed that the income and wealth distribution was close to the Gibbs distribution of energy of an ideal gas. Although there are similarities between the collision theory of the ideal gas and the Random Walk price dynamics of the trading market, the interaction between agents in the trading market can deviate from the collision theory because of the properties of the self-organized market and uncertain human behaviour.

The fat tails of the return distribution were intensively investigated by Fisher and Tippett (1928) using Extreme Value Theory. The fat tails of the return distribution are usually parameterized by Generalized Pareto distribution. Obviously, Extreme Value Theory cannot describe the non-random stock behavior with negative trend of the stock price. Moreover, the application of the complicated mathematical functions, for example Pareto distribution, for fitting of the return distribution cannot explain the nature of the market panic phenomena.

The value of the trading volume is the most important indicator of the stock market, which quantifies the supply and demand intersection for the price equilibrium. The dynamics of the trading volume are widely used in the technical analysis. Blume, Easly and O'Hara (1994) investigated the application of the trading volume in the technical analysis from the ability of technical analysts to predict the liquidity and stability of the equity market. 
The trading volume in the technical analysis is analyzed with the information of the growth or decline of the stock price movement, for example, Caginalpa and Desantisa (2011) pointed out that if the stock price is growing, but the trading volume is declining, stock price growth is considered by technical analysts as unstable.

The analysis of the price and trading movements can distinguish the bearish and bullish markets and investors sentiments about stocks, since the inverse dependence of the volume of shares on the stock price is defined from the interactions of the demand and supply curves. Chordia, Subrahmanyam and Anshuman (2001) and Baker and Wurgler (2007) investigated the relationship between the investor sentiment and stock price returns. Baker and Stein (2004) developed the model of the secondary market liquidity related to the price impact for the prediction of the returns.

Admati and Peiderer (1988) presented a model, in which concentrated-trading patterns arise endogenously as a result of the strategic behavior of liquidity traders and informed traders. Admati and Peiderer (1988) provided a partial explanation for some of the empirical findings concerning the patterns of volume and price variability in intraday transaction data. Huddart, Lang and Yetmen (2009) used large sample data of stock price and trading volume using technical analysis. Huddart, Lang and Yetmen (2009) found that the trading volume was strikingly higher, in both economic and statistical terms, when the stock price crossed either the upper or lower limit of its past trading range. The price returns were reliably positive and, among small investors, trades classified as buyer-initiated are elevated. Chen, Hong, and Stein (2001) developed a series of cross-sectional regression specifications to forecast skewness in the daily returns of individual stocks. They empirically observed the relationship between positive/negative skewness of the stock price return and the trading volume relative to trend over the prior six months. Goetzmann and Massa (2008) used a large sample of individual accounts over a six-year period in 1990's to find a direct link between individual investor behavior and asset price dynamics. Goetzmann and Massa (2008) showed that aggregated factors from individual investment decisions are statistically related to returns, volume and volatility. Lee and Swaminathan (2008) showed that the historical volume improves to reconcile intermediate-horizon "underreaction" and long-horizon "overreaction" effects.

The empirical dependence of trading volume on the stock price return was studied by Lo and Wang (2006) and Llorente, Michaely, Saar (2002). Llorente, Michaely and Saar (2002) propose the model, for which the trading process is driven by investor's expectations of the future stock price returns and exposure to the risk in equilibrium conditions. Lo and Wang (2006) describe an intertemporal equilibrium model of stock trading and pricing with multiple assets and heterogeneous investors.

Although the inverse dependence of trading volume on the stock price for market crashes is well-known, the study of dependence of the trading volume on stock price movement during market crashes has received relatively little attention in the academic literature. The aim of this work was to study the trading volume behaviour during market crashes and the impact of the stock price declines on the growth of the trading volume. The main goal of this work is to use an analytical approach in the description of the trading volume and stock price so that the basic features of the market trading process between buyers and sellers can be determined.

We present a model which incorporates the mechanism of the cash-flow exchange between buyers and sellers via trading shares in the stock market. In this work, we employ both analytical approach and Monte-Carlo techniques to describe the general relations between the stock price and trading volume during market crashes. The aim of this work was to study the extreme market conditions and their impact on the dynamics of the stock price and trading volume. The model may potentially explain the stock price dynamics at the market crashes.

\section{The Model}

The trading process can be viewed as an exchange of cash and shares between market participants. The exchange between buyers and sellers is driven by different views for the valuation of the shares, with the buyers viewing the shares as undervalued, and the sellers viewing them as overvalued. We assume that the buyer intends to spend $C_{a}$ in cash on the shares of a particular stock, and values the undervalued stock at $P_{b}$. Then we can define his hypothetical number of shares as:

$$
A_{b}=\frac{C_{a}}{P_{b}}
$$

The number of shares $A_{s}$ is known for a seller $s$. The proposed assumption of the hypothetical buyer's shares allows us to apply the interaction between the buyers and shares in the same dimensionality. 
The trading exchange may occur for the specific time interval with the probabilistic function $R$, which will be called the exchange rate. The rate of interaction between two groups of agents will be proportional to the shares $A_{b}, A_{s}$, and the exchange rate, which is defined by the probabilistic function $R_{i}$.

The rate of interaction for shares at time $t$ can be expressed as:

$$
J_{i}=R_{i} A_{b, i} A_{s, i}
$$

where $J_{i}$ is the number of elementary exchanged shares. The total exchange volume is

$$
J=\sum_{i=1}^{N} R_{i} A_{b, i} A_{s, i}
$$

where $N$ is the number of sets of buyers and sellers, $J$ is the total number of trades for a specific time interval, i.e. the trading volume. In contrast to the model of the kinetic exchange of the wealth suggested by Chatterjee and Chakrabarti (2007), the current model does not assume that the properties of the trading market are similar to the properties of the ideal gas phase. According to the reflexivity approach developed by Soros (1987), participant understanding of the market is imperfect with different expectation views of the stock price valuation. Therefore, the exchange rates, $R_{i}$, are the stochastic functions, which describe the expectation view of the market participants. If the stock market is in the equilibrium, then Equation (3) describes the stochastic process of the trading volume.

Panic market conditions are characterized by the properties of the self-organized market, for which almost all agents have similar expectations of the stock price decline (Soros, 1987). Applications of the various hedging strategies to survive the money paper wealth are very limited because of the limited number of investors, which want to buy the shares with low credit quality or set of seller of the shares significantly exceeds the portion of the market participants, which want to buy. In this case, the expectation prices of the buyers are almost the same for different groups of agents; moreover, the exchange rates $R_{i}$ are assumed almost the same:

$$
R_{1} \approx R_{2} \approx \ldots \approx R_{N}
$$

It is necessary to take into account that for the panic market conditions, the expectation price of the buyers is defined by the current stock price of the market. Therefore, the equation of the total trading volume is simplified:

$$
J=R \sum_{i=1}^{N} A_{b, i} A_{s, i}
$$

We can conclude that the cash balance exists between sellers and buyers during trading. Therefore, using Equations (1) and (5) and cash balance, i.e. the sellers convert existing shares $A_{s i}$ to the cash with price $P$, we have:

$$
J=R \sum_{i=1}^{N} \frac{C_{i}}{P} A_{s, i}=R \sum_{i=1}^{N} \frac{C_{i}}{P} \frac{C_{i}}{P}=\frac{R}{P^{2}} \sum_{i=1}^{N} C_{i}^{2}
$$

Since the money market is much larger than the market of the given shares, the impact of the depreciation of the shares cannot significantly influence the money market. Therefore, the trading volume is almost independent from the money market. Thus, Equation (6) can be simplified:

$$
J=R_{c} \frac{1}{P^{2}}
$$

where

$$
R_{c}=R \sum_{i=1}^{N} C_{i}^{2} \approx \text { const }
$$

Thus, we can see that two main regimes of stock price movement may exist: stochastic dynamics, Equation (3), and price-driven dynamics, Equation (7). Obviously, Equation (7) describes the ideal case, when all agents follow the same law of market panic condition. If the process doesn't follow the conditions $(4,8)$, the trading volume follows the random-walk movement. 


\section{Results}

\subsection{Monte-Carlo Simulation of the Trading Volume}

To understand the trading process between buyers and sellers for shocking market conditions, we developed a Monte-Carlo technique (MC) for the simulation of the trading volume (MCTV). The MCTV simulation gives useful information of the relationship between the trading volume and stock price in the case of the equilibrium of the cash-share exchange between buyers and sellers.

To describe the elementary process, the geometric Brownian motion of the stock price was applied to establish the stock price stochastic process, i.e. the stock price can migrate in random directions with volatility $\sigma$ with initial price $P_{0}$. The initial cash volume for trading was selected, $C_{0}$. The total number of shares for each trading was calculated from the equation:

$$
A(t)=\frac{C_{0}}{P(t)}
$$

The sellers may exchange shares for cash and buyers may exchange cash for shares in a homogeneous medium with probability $\operatorname{Pr}_{\text {seller }}$ and $\operatorname{Pr}_{\text {buyer }}$, respectively. The probabilities $\operatorname{Pr}_{\text {seller }}$ and $\operatorname{Pr}_{\text {buyer }}$ were defined from cumulative log-normal distribution with mean $\ln \left(P_{0}\right)$ and standard deviations $\sigma_{s}$ and $\sigma_{b}$, respectively:

$$
\begin{gathered}
\operatorname{Pr}_{\text {seller }}=F\left(\ln (P(t)), \ln \left(P_{0}\right), \sigma_{s}\right) \\
\operatorname{Pr}_{\text {buyer }}=1-F\left(\ln (P(t)), \ln \left(P_{0}\right), \sigma_{b}\right)
\end{gathered}
$$

Equations $(10,11)$ described the rational behaviours of buyers and sellers, for example, the probability $\operatorname{Pr}_{\text {buyer }}$ increases as the stock price decreases and the probability $\operatorname{Pr}_{\text {seller }}$ decreases as the stock price decreases. All pairs of shares from buyers and sellers were monitored to count the trading events. The elementary trade for each pair from $A_{b}$ and $A_{s}$ was observed, if the Bernoulli trial probability did not exceed the product $\operatorname{Pr}_{\text {seller }} \operatorname{Pr}_{\text {buyer }}$. Then, the elementary trading events were summarized for each simulated stock price $P(t)$. One simulation period was called as the simulated trading day. The simulation of the daily trading volumes were carried out for 10000 times and repeated 100 times for different trading days with the given initial conditions. The periodic time boundary conditions for different trading days were established. The MC measurements of the dependence of the daily trading volume on the daily last price were monitored after the simulated elementary cash-share exchange.

The proposed MCTV simulation technique differed from the agent-based model of the trading volume proposed by Palmer et al. (1994) and Chen and Liao (2005). According to our MCTV method, the trading volume was driven by the stochastic process of the stock price and stock price does not depend on the trading volume. The MCTV technique applied the simulation of the elementary process of cash-share trading exchange taking into account the properties of the market agents as the properties of the self-organized market.

Our MCTV method did not contradict to the no-arbitrage principle of the equity market, since the trading volume is driven by the dynamics of the stock price as geometric Brownian motion. No-arbitrage condition was confirmed by the Monte-Carlo measurements of the total cash balance between buyers and sellers for the period of the 100 simulated trading days: the testing of null hypothesis of the zero cash balance showed that the p-value was less than $2 \%$.

Ideally, the simulation of trading process should include the simulation of the market system, such as an order-driven market, however, we assumed that the elementary trading exchange occurs irreversibly and instantaneously without interface resistance between buyers and sellers through the market system. The simulation of the market system is out of scope for the work. The measured trading volume for each stock price can be considered as ex-post data, when the steady-state equilibrium of price-volume was reached.

To test the inverse price squared dependence, Equation (7) was transformed in the form:

$$
\operatorname{Ln}(J)=a+k \operatorname{Ln}(P)
$$

where $a$ is the trading cash term, i.e. $a=\operatorname{Ln}\left(R_{c}\right), k$ is the slope parameter for the test of $k=-2$.

The observed slope coefficient is calculated from the expression:

$$
k_{o b s}=\frac{d \operatorname{Ln}(J)}{d \operatorname{Ln}(P)}
$$

$k_{o b s}$ is the measured slope coefficient. 
From Equation (12), the observed slope coefficient consists of the constant term and the term, which can depends on the trading cash, which can actually be a random parameter:

$$
k_{\text {obs }}=-2+\frac{d a}{d \operatorname{Ln}(P)}
$$

As can been seen from Equation (14), the observed slope coefficient can be changed in the high range, if (1) the stochastic stock price movement is in the small range, and (2) if the trading cash follows the random-walk movement. In our work, we investigate the shocking market conditions, when stock prices change in the large range and stock market follows the herd behavior. Therefore, two stock price dynamics were investigated in the MC simulation. For the first simulation condition, the initial stock price was constant and was equal to artificial 10 currency units (CU) per share with constant trading cash. For the second simulated trading process, the initial stock price was linearly changed for each trading days (30 days) from $5 \mathrm{CU}$ per share to $100 \mathrm{CU}$ per share with constant trading cash.

The trading cash amount was equal to the artificial 1000 currency units (CU) for MCTV simulation. If the initial equilibrium price of $10 \mathrm{CU} /$ share, the initial pool of shares supplied by the seller was 100 shares. The initial total number of pairs of shares (buyer-sellers) was equal to 10000 . The stochastic process of the stock price was simulated with zero drift, volatility $0.01 \%$ and step-time 0.01 . The standard deviations $\sigma_{s}$ and $\sigma_{b}$ were equal to $0.575 \mathrm{CU}$. After 10000 simulations, the trading volume and the last price were measured for 1 simulated trading day.

Figure 1 summarizes the results of the simulation of the trading volume as the dependence of the trading volume on the stock price in the logarithmic scale. Figure 1a represents the simulation of the trading volume in the case of the constant initial stock price of $10 \mathrm{CU}$ per share for different trading days. As we expected, the trading volume exhibited the random-walk process in the case of the stochastic process of the stock price, Figure 1a. In contrast to the random-walk process, Figure $1 \mathrm{~b}$ shows the dependence of the simulated trading volume on the different initial daily stock prices from $5 \mathrm{CU}$ per share to $100 \mathrm{CU}$ per share (b). Liner dependence of $\ln (J)$ on $\ln (P)$ was clearly observed according to Equation (7) with slope coefficient close to (-2). Thus, if the initial stock prices change in the high range with constant trading cash, the dependence of the simulated trading volume vs. $1 / P^{2}$ is clearly monitored, see Figure $1 \mathrm{~b}$.

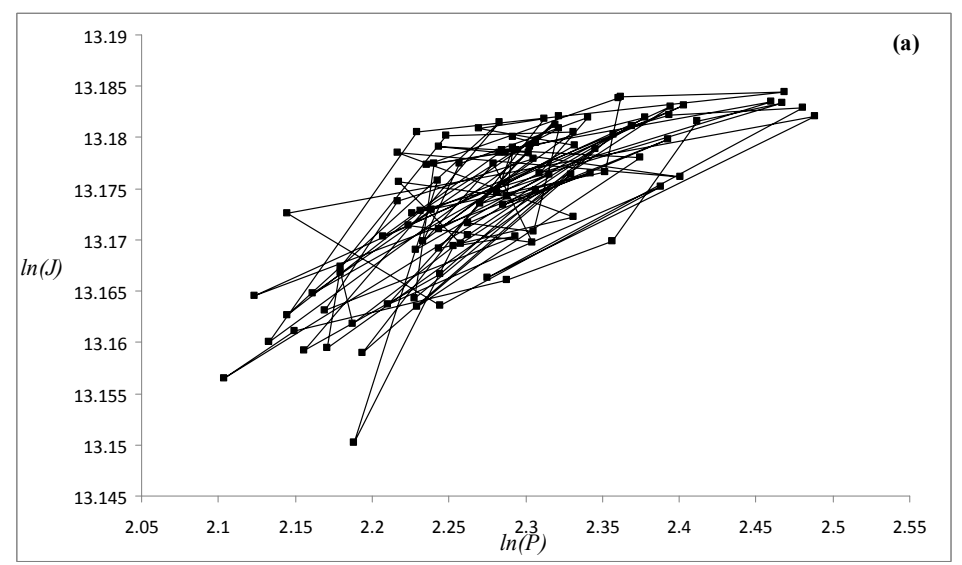




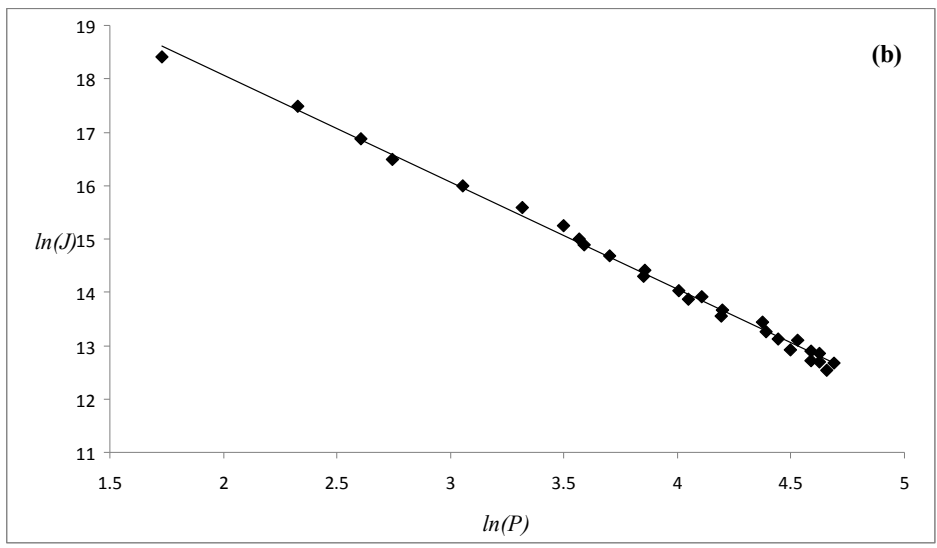

Figure 1. The results of the Monte-Carlo simulation of the trading volume as dependence of the trading volume on the stock price

Note: Two stock price dynamics were investigated in the MC simulation. For the first simulation condition (a), the initial stock price was constant and was equal to $10 \mathrm{CU}$ per share (a). For the second process (b), the initial stock price was linearly changed for each trading days (30 days) from 2 to $100 \mathrm{CU}$ per share.

\subsection{Empirical Tests at the Market Crashes}

We now test our model on major bankruptcies in of US stocks during the most recent crises. We consider monthly and daily prices and volume data for each stock during the period of its respective collapse. The following companies are considered: Lehman Brothers Inc, Enron, Wachovia, Washington Mutual, and MF Global. We also investigated the sharp price declines of two companies during market crisis: Citigroup and Merrill Lynch.

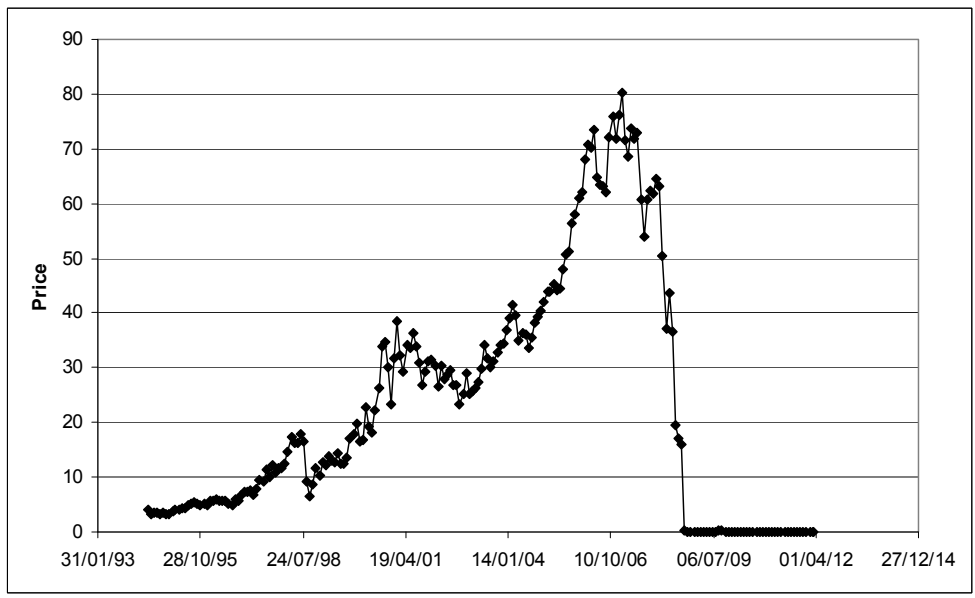

Figure 2. Monthly stock price of Lehman Brothers Inc. (Bloomberg data)

Figure 2 shows the historical prices of Lehman Brothers Inc. The historical stock prices data of Lehman Brothers are characterized by the sharp stock price decline since 31/01/2007 followed by the stock price growth with random walk. Figures 3 and 4 show the dependence of natural logarithm of trading volume on the natural logarithm of the stock prices for two cases: stock price growth for period from 31/08/04 to 30/11/06 and the price decline from $31 / 01 / 2007$ to $29 / 08 / 2008$, respectively. It is interesting to observe the stochastic process and the linear dependence for these two cases. 


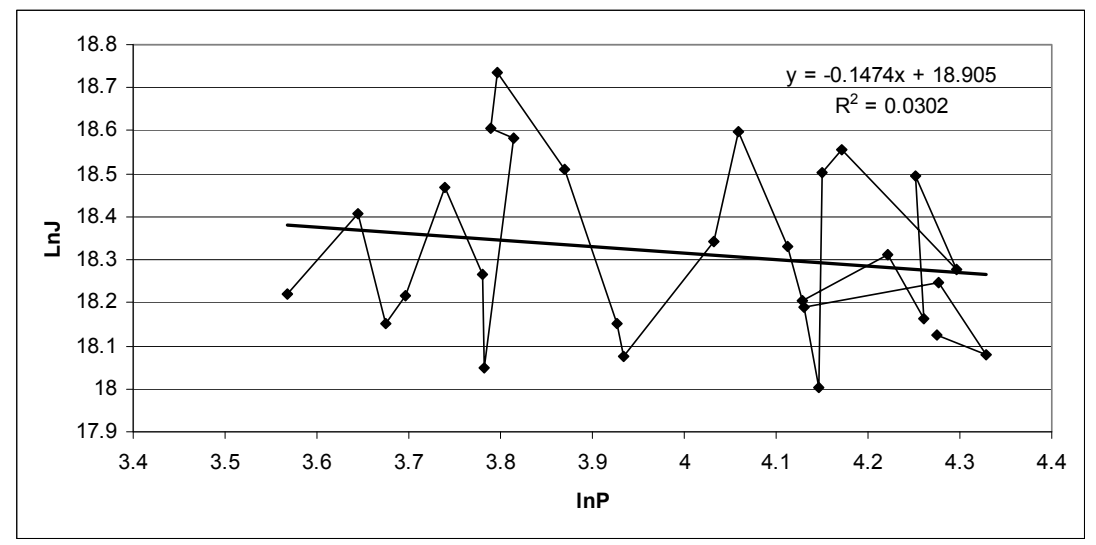

Figure 3. The data pattern from 31/08/04 to 30/11/06 as dependence of $\operatorname{Ln}(J)$ vs. $\operatorname{Ln}(P)$ for Lehman Brothers. Random-walk process of the volume vs. stock price with positive trend of the stock price is observed.

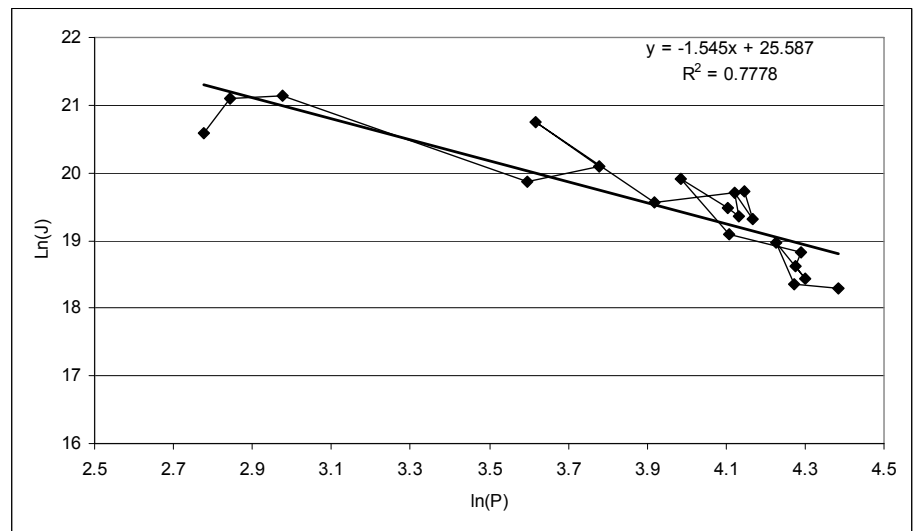

Figure 4. Sharp price decline of Lehman Brothers from 31/01/2007 to 29/08/2008. Trading volume and stock price dependence in the logarithmic scale. Liner dependence of $\operatorname{Ln}(J)$ on $\operatorname{Ln}(P)$ is observed according to Equation (7).

For the regression analysis, we can select stock price data from the price peak to the minimum price data in the slope. Although our data selection could include the outliers, this approach was considered as more unbiased. From the regression analysis, the sharp price decline of Lehman Brothers is characterized by the slope coefficient -1.55 , which is close to the theoretical predicted value -2, see Figure 4. Since we don't know the time interval of the panic behaviour of the agents, we don't know the perfect time frame for the regression analysis. We can select the pattern inside in the slope, in this case the slope coefficient will be very close -2 , but this approach would be biased. The difference between observed slope coefficient (-1.55) and theoretical value (-2) can also be explained by the stochastic term, see Equation (14), which is related to the assumption that not all agents follow the herd behavior (in the case of the contribution of the stochastic term, the coefficient $k>-2$ ).

To exclude survivorship bias in our analysis, we used two statistical filters. Fist filter excluded slope coefficients data, which were statistically insignificant from the test of rejection of null hypothesis with level of significance $5 \%$. Second filter selected the stable stock price decline pattern; for example, for daily data prices the arithmetic average, of the daily stock price returns was calculated for the time frame of 47 business days (for monthly data, 12 month average was used). This second filter selected slope coefficients data, if the average returns were lower than (-0.001). These two filters provided the robust empirical test of the regression parameters. The time frames for regression analysis were 12 month and 100 days for monthly data and daily data, respectively.

Figures 5 and 6 show the time dependence of average return and slope confidents for Enron and Citigroup during market crashes in 2001 and 2007. As can been seen, the slope coefficients asymptotically reached the level of (-2) with degreasing stock price returns. Thus, the empirical tests clearly confirmed the inverse dependence between trading volume and the stock price during market crashes. 
Similar linear dependences between trading volume and inversely proportional to the square of the stock price were observed for companies with credit events: Merrill Lynch, Enron, Wachovia, Washington Mutual, and MF Global. We selected the slope coefficients data with the minimum average return. Table 1 summarizes the results of the regression tests.

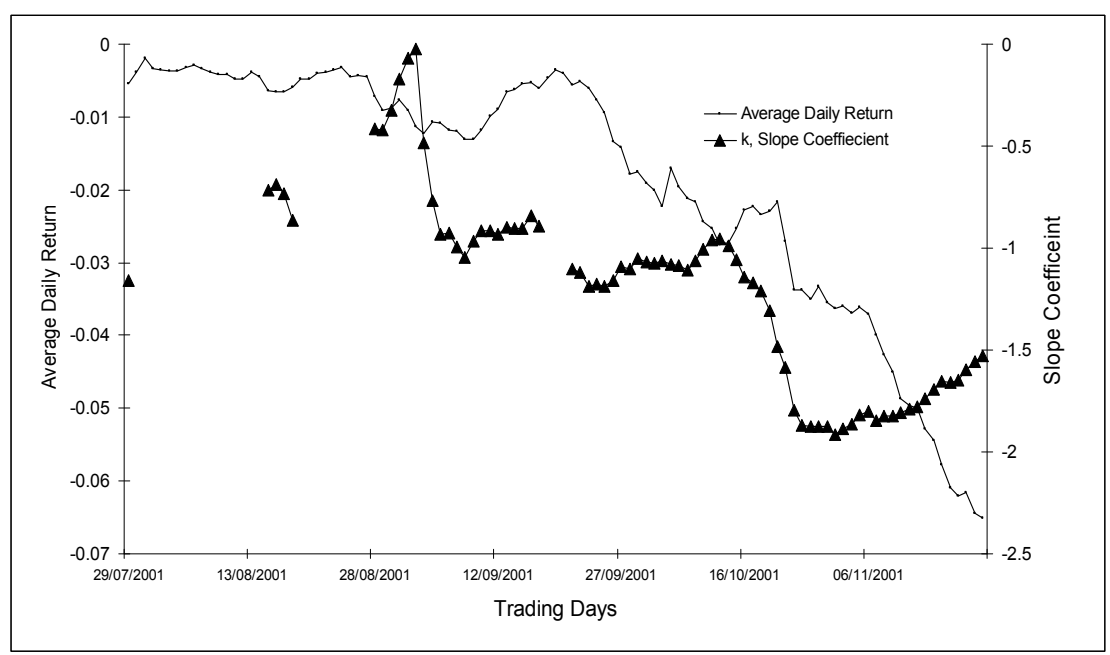

Figure 5. The time dependence of the average return and slope coefficient for Enron

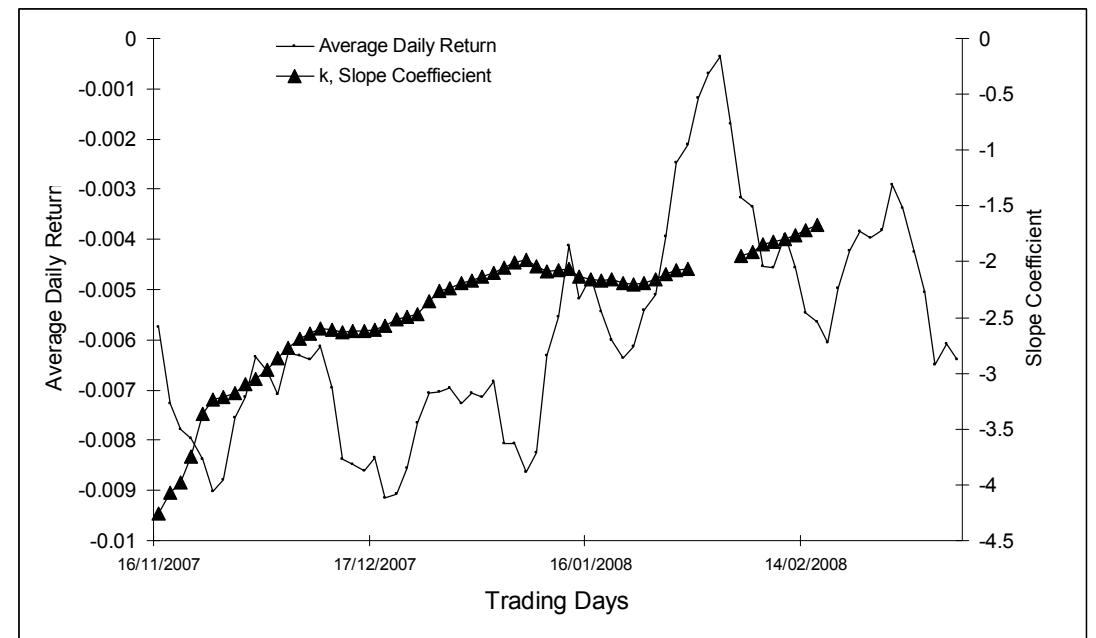

Figure 6. The time dependence of the average return and slope coefficient for Citigroup during financial crisis

Table 1. Summary of the regression tests (Observed slope coefficients were close to the predicted coefficient -2)

\begin{tabular}{ccccccc}
\hline Company & $\begin{array}{c}\text { Slope } \\
\text { Coefficient, } \mathrm{k}\end{array}$ & $\begin{array}{c}\text { Standard } \\
\text { Error }\end{array}$ & $R$-square & $\begin{array}{c}\text { Minimum } \\
\text { Average } \\
\text { Return }\end{array}$ & Date & comment \\
\hline Enron & -1.53 & 0.08 & 0.78 & -0.065 & $27 / 11 / 2001$ & Daily data \\
Citigroup & -2.58 & 0.26 & 0.50 & -0.009 & $18 / 12 / 2007$ & Daily data \\
Merrill Lynch & -1.68 & 0.21 & 0.39 & -0.009 & $30 / 07 / 2008$ & Daily data \\
Lehman Brothers & -1.50 & 0.24 & 0.79 & -0.086 & $30 / 06 / 2008$ & Monthly data \\
Wachovia & -1.45 & 0.27 & 0.74 & -0.082 & $30 / 06 / 2008$ & Monthly data \\
Washington Mutual & -1.78 & 0.26 & 0.82 & -0.054 & $31 / 12 / 2007$ & Monthly data \\
MF Global & -1.78 & 0.73 & 0.38 & -0.011 & $31 / 08 / 2011$ & Monthly data \\
\hline
\end{tabular}

Data source: Google Finance, Yahoo Finance, Bloomberg. 


\section{Discussion}

The empirical and numerical tests clearly confirmed the analytical dependence of the trading volume on the inversely proportional square of the stock price for the sharp price decline. As can been seen from Table 1, the linear dependence of $\operatorname{Ln}(J)$ vs. $\operatorname{Ln}(P)$ is statistically significant, therefore we can conclude that the trading cash flows were stable in the cash-share exchange process during market crisis.

The cash-shares exchange can be viewed as the cash-share cycle through three main cash-shares flows: the share supply flow for trading $\left(J_{1, i}\right)$, the exchange flow $\left(J_{2, i}\right)$, and the cash supply flow for trading or demand flow $\left(J_{3, i}\right)$. We consider two types of outstanding shares: actively traded outstanding shares or shares for short-term trading and non-actively traded outstanding shares. The schematic diagram of the cash-shares exchange is presented in Figure 7.

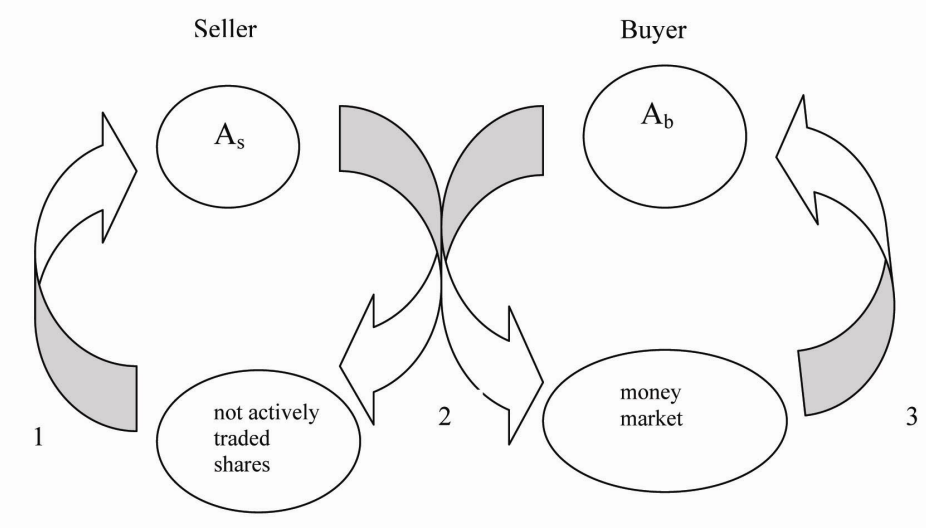

Figure 7. Cash-share exchange scheme

According to the proposed kinetic scheme, the cash and share volumes can be estimated by the solution of kinetic equations for the specific group of agents $i$ :

$$
\begin{aligned}
& \frac{d A_{b, i}}{d t}=J_{3, i}-J_{2, i} \\
& \frac{d A_{s, i}}{d t}=J_{1, i}-J_{2, i}
\end{aligned}
$$

For the panic market, $J_{1, i}>>J_{2, i}$; and the rate of total process will be limited by the slow exchange flow $J_{2, i}$.

The kinetic scheme of the share-cash exchange can also be applied for the boom market. As can been seen from kinetic Equations $(15,16)$, the price growth can be explained by decreasing the share supply flow $J_{1, i}$ or by increasing cash flow $J_{3, i}$. In contrast to the market panic conditions, the boom market is characterized by different buyer's expectations of the stock price.

\section{Conclusion}

We have analytically shown that during market crises, trading volume is inversely proportional to the square of the stock price. We have presented strong empirical evidence for this result by considering monthly price and volume data for major US stock crashes over the past decade. The analytical dependence between trading volume and inversely proportional to the square of the stock price can be used as a bankrupt indicator.

\section{References}

Admati, A. R., \& Peiderer, P. (1988). A theory of intraday patterns: Volume and price variability. The Review of Financial Studies, 1(1), 3-40. http://dx.doi.org/10.1093/rfs/1.1.3

Bachelier, L. (1900). Theorie de la speculation. PhD thesis. Universite Paris Sorbonne.

Baker, M., \& Stein, J. C. (2004), Market liquidity as a sentiment indicator. Journal of Financial Markets, 7 , 271-299. http://dx.doi.org/10.1016/j.finmar.2003.11.005 
Baker, M., \& Wurgler, J. (2007). Investor Sentiment in the Stock Market. Journal of Economic Perspectives, 21(2), 129-151. http://dx.doi.org/10.1257/jep.21.2.129

Black, F., \& Scholes, M. (1973). The Pricing of Options and Corporate Liabilities. The Journal of Political Economy, 81(3), 637-654. http://dx.doi.org/10.1086/260062

Blume, L., Easley, D., \& O'Hara, M. (1994). Market Statistics and Technical Analysis: The Role of Volume. Journal of Finance, 49(1), 153-181. http://dx.doi.org/10.1111/j.1540-6261.1994.tb04424.x

Brennan, M. J., Chordia, T., \& Subrahmanyam, A. (1998). Alternative Factor Specifications, Security Characteristics, and the Cross-Section of Expected Stock Returns. Journal of Financial Economics, 49, 345-373. http://dx.doi.org/10.1016/S0304-405X(98)00028-2

Caginalpa, G., \& Desantisa, M. (2011). Stock price dynamics: nonlinear trend, volume, volatility, resistance and money supply. Quantitative Finance, 11(6), 849-861. http://dx.doi.org/10.1080/14697680903220356

Chatterjee, A., \& Chakrabarti, B. K. (2007). Kinetic exchange models for income and wealth distributions. Eur. Phys. J. B, 60, 135-149. http://dx.doi.org/10.1140/epjb/e2007-00343-8

Chen, J., Hong, H., \& Stein, J. C. (September 2001). Forecasting crashes: trading volume, past returns, and conditional skewness in stock prices Original Research Article. Journal of Financial Economics, 61(3), 345-381. http://dx.doi.org/10.1016/S0304-405X(01)00066-6

Chen, S.-H., \& Liao, C.-C. (2005). Agent-based computational modeling of the stock price-volume relation, Information Sciences, 170, 75-100. http://dx.doi.org/10.1016/j.ins.2003.03.026

Chordia, T., Subrahmanyam, A., \& Anshuman, V. R. (2001). Trading Activity and Expected Stock Returns, Journal of Financial Economics, 59, 3-32. http://dx.doi.org/10.1016/S0304-405X(00)00080-5

Fisher, R. A., \& Tippett, L. H. C. (1928). Limiting forms of the frequency distribution of the largest and smallest member of a sample. Proc. Camb. Phil. Soc., 24, 180-190. http://dx.doi.org/10.1017/S0305004100015681

Goetzmann, W. N., \& Massa, M. (2008). Disposition matters: volume, volatility, and price impact of a behavioural bias. The Journal of Portfolio Management, 34(2), 103-125. http://dx.doi.org/10.3905/jpm.2008.701622

Huddart, S., Lang, M., \& Yetman, M. H. (January 2009). Volume and Price Patterns Around a Stock's 52-Week Highs and Lows: Theory and Evidence. Management Science, 55(1). http://dx.doi.org/10.1287/mnsc.1080.0920

Lee, C. M. C., \& Swaminathan, B. (October 2000). Price Momentum and Trading Volume. The Journal of Finance, 55(5), 2017-2069. http://dx.doi.org/10.1111/0022-1082.00280

Llorente, G., Michaely, R., \& Saar, G. (2002). Dynamic Volume-Return Relations of Individual Stocks. Review of Financial Studies, 15, 1005-1047. http://dx.doi.org/10.1093/rfs/15.4.1005

Lo, A. W., \& MacKinlay, A. C. (1988). Stock Market Prices do not Follow Random Walks: Evidence from a Simple Specification Test. Review of Financial Studies, 1, 41-66. http://dx.doi.org/10.1093/rfs/1.1.41

Lo, A. W., \& Wang, J. (2006). Trading Volume: Implications of an Intertemporal Capiral Asset Pricing Model. Journal of Finance, 61, 2805-2840. http://dx.doi.org/10.1111/j.1540-6261.2006.01005.x

Mandelbrot, B. (1963). The variation of certain speculative prices. J. Business, 36, 394-419. Harvard University, Cambridge, MA and Research Center, International Business Machines Corp. http://dx.doi.org/10.1086/294632

Palmer, R. F., Arthur, W. B., Holland, J. H., LeBaron, B., \& Tayler, P. (1994). Artificial economic life: a simple model of a stock market. Physica D, 75, 264-274. http://dx.doi.org/10.1016/0167-2789(94)90287-9

Soros, G. (1987, 2003). The Alchemy of Finance. Wiley \& Sons, Incorporated, John.

\section{Copyrights}

Copyright for this article is retained by the author(s), with first publication rights granted to the journal.

This is an open-access article distributed under the terms and conditions of the Creative Commons Attribution license (http://creativecommons.org/licenses/by/3.0/). 